\title{
Analysis of Dandong 99 strawberry market competitiveness Based on Porter's five forces model
}

\author{
Qian Kun ${ }^{1, a}$, Lv Yuenan ${ }^{2, b}$, Li Yingxue ${ }^{3, c}$ \\ ${ }^{1}$ School of Management Dalian Polytechnic University, DLPU Dalian China \\ ${ }^{2}$ School of Management Dalian Polytechnic University, DLPU Dalian China \\ ${ }^{3}$ School of Management Dalian Polytechnic University, DLPU Dalian China
}

\begin{abstract}
In this paper, using the potter five models, from the buyers bargaining power, the bargaining power of suppliers, the threat of potential entrants, the threat of substitutes and industry competition ability five aspects of current competitors within the market competitiveness of dandong 99 strawberry is analyzed, on the basis of the existing problems and put forward the corresponding countermeasures and Suggestions, in order to enhance the competitiveness of the dandong 99 strawberry play a role in promoting.
\end{abstract}

\section{INTRODUCTION}

In ancient China, agriculture was the foundation of the country. Since ancient times, agriculture has been the focus of China's development. In 2017, the report to the 19th National Congress of the CPC pointed out that the issues of agriculture, rural areas and farmers are fundamental issues affecting the national economy and people's livelihood. We must always make solving these issues the top priority in the work of the Whole Party. To implement the strategy for rural revitalization, we will give priority to the development of agriculture and rural areas, establish sound systems, mechanisms and policies for integrated urban and rural development, and accelerate the modernization of agriculture and rural areas in accordance with the overall requirements of thriving industries, livable ecosystems, civilized rural practices, effective governance, and prosperous lifestyles. We will establish a modern system of agricultural industry, production and operation, improve the system of support and protection for agriculture, develop various forms of appropriately scale-scale operations, foster new types of agricultural operators, improve the system of socialized agricultural services, and integrate the development of small farmers with that of modern agriculture.

Dandong, located at 40 degrees north latitude, is recognized as the most suitable region for strawberry growth. The natural geographical environment ensures the quality of strawberries. Dandong quite a lot of strawberry varieties, mainly 99, Zhangji, Hani, Fengxiang and so on.Among them, 99 strawberry because of abundant in winter, sweet taste, in the market has quite high popularity. In 2019, the city's total strawberry production area reached $171,200 \mathrm{mu}$, the total output reached 420,000 tons, the output value exceeded 3.5 billion yuan, the output and area accounted for $13.62 \%$ and $9.51 \%$ of the national total, respectively. The scale of blackberry industry ranks first in China. But with the rapid growth of strawberry production and sales, competition in the industry intensified ${ }^{[1]}$. Based on Porter's five Forces model, this paper analyzes the competitiveness of Dandong 99 strawberry in the market in order to promote the healthy and sustainable development of the strawberry market.

\section{ANALYSIS OF POTER'S FIVE FORCES MODEL IN DANDONG 99 STRAWBERRY MARKET}

\subsection{Introduction to Porter's five forces model}

Michael E. Porter, as the father of enterprise competitive strategy and the founder of modern competitive strategy, put forward the five forces model in the early 1980s, aiming to create a new analysis mode for the strategic analysis of enterprises. The so-called five force model consists of five parts: the bargaining power of buyers, the bargaining power of suppliers, the threat of substitutes, the threat of potential entrants and the competitiveness of existing competitors in the industry ${ }^{[2]}$. Porter believes that these five forces determine the scale and degree of competition in the industry, and their common strength has an impact on the existing competitive strategic decision-making and industry attractiveness. The details are shown in Figure 1. 


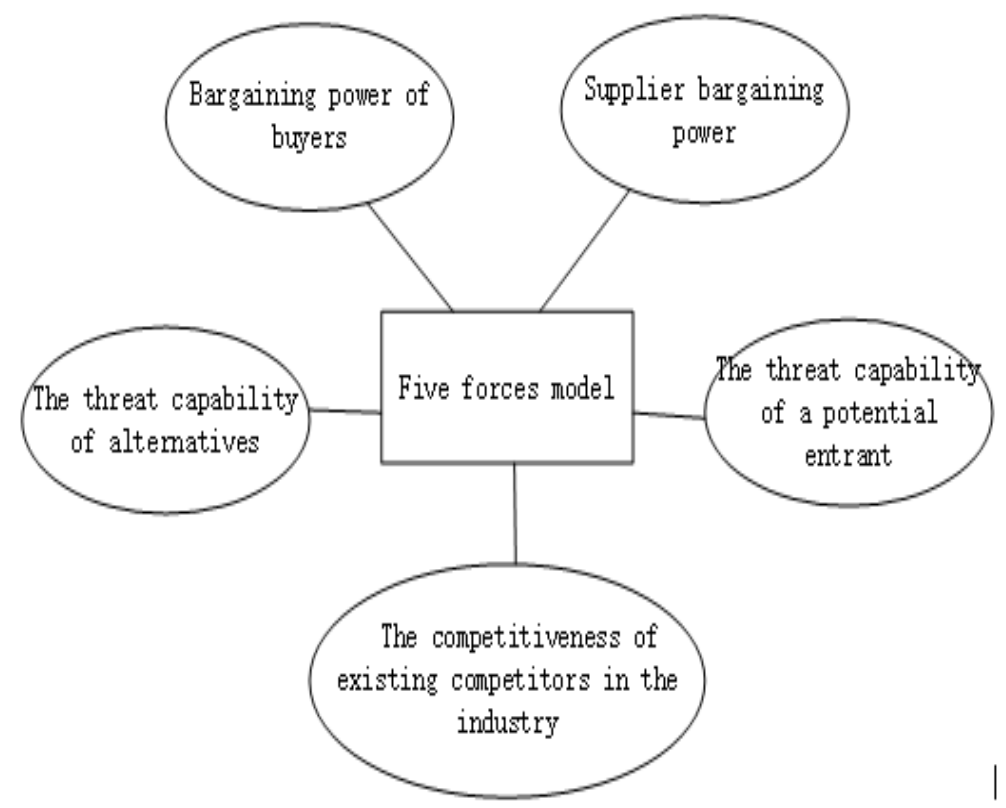

Figure 1. Porter's five forces model

\subsection{Analysis of Porter's five forces model in Dandong 99 strawberry market}

According to the basic theory of Porter's five forces model, this paper analyzes the market competitiveness of 99 strawberry, as shown in Figure 2:

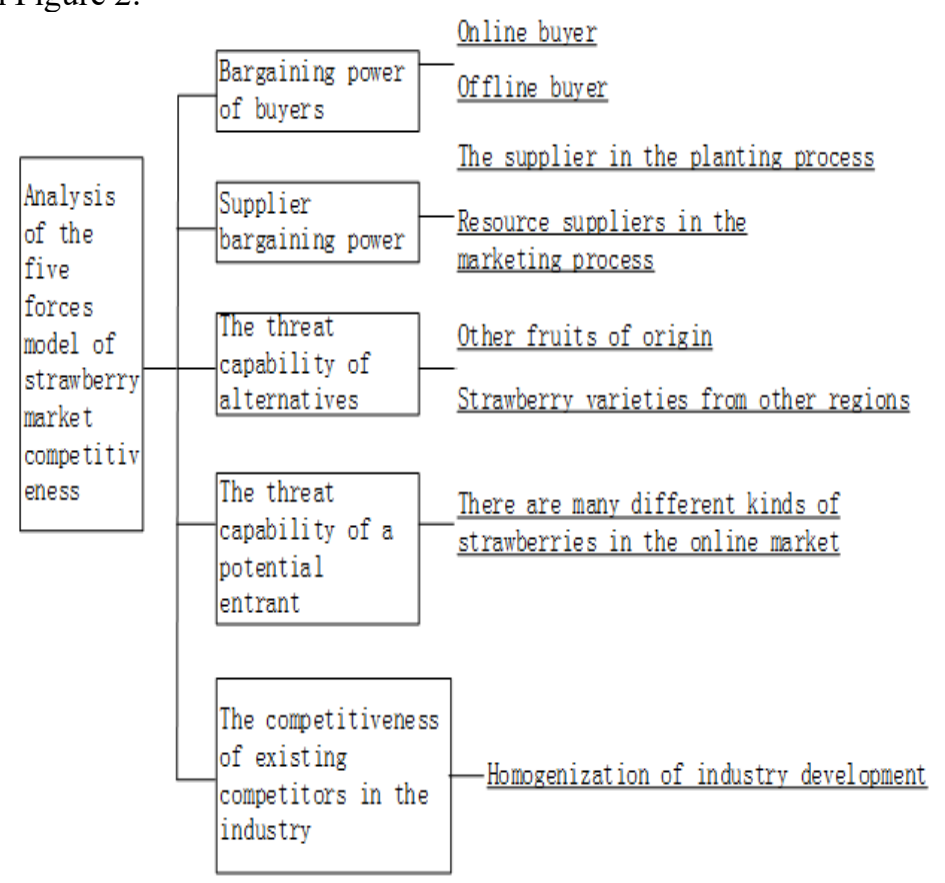

Figure 2. Porter's five forces model in Dandong 99 strawberry market

\subsubsection{Bargaining power of buyers.}

At present, Dandong 99 strawberry sales model is mainly divided into online and offline two $^{[3]}$. The main characteristics of offline buyers are weak consumption ability and high liquidity; while the main characteristics of online buyers are: wide range of choices, strong ability to obtain information, small amount of purchase, low customer loyalty. Strawberry, as a kind of fruit, is a kind of non life necessities. Therefore, whether it is sold online or offline, there are many kinds of substitutes and low cost for buyers to choose. Therefore, the overall bargaining power of buyers is strong, which makes the sales pricing of 99 strawberry in the market basically stable, and the profit floating space is low. 


\subsubsection{Bargaining power of suppliers.}

The suppliers mainly include the suppliers in the planting process and the resource suppliers in the marketing process $^{[4]}$.

\subsubsection{Suppliers in the process of planting}

The suppliers in the process of planting mainly include strawberry seedling growers; labor force such as planting and picking; fertilizer and drug suppliers; agricultural machinery and agricultural tools suppliers. Due to the rapid growth of strawberry growers in recent years, the number of strawberry seedling growers also increased. The matching between the number of strawberry growers and the number of strawberry seedling growers affects the price of strawberry seedlings. If affected by weather and other natural factors, the survival rate of strawberry seedlings is not high, which will lead to the price rise of strawberry seedlings. It is difficult for strawberry growers to plant seedlings on time, delay the listing time of strawberries and miss the best sales opportunity. However, with the development of science and technology, there are more and more strawberry seedlings preserved by freezing technology in the market. The survival rate of these strawberry seedlings is high, and the strawberry is listed early, but the cost price is relatively high, which increases the planting cost of strawberry growers. In addition, due to seasonal restrictions on strawberry planting, planting and ripening time is relatively concentrated, and the rural labor force is limited, planting and picking personnel are in short supply, which leads to the increase of labor cost. In addition, in the busy season, the demand for high-quality fertilizers, pesticides and agricultural machinery and tools is increasing, which often exceeds the demand, so the raw material cost of strawberry growers increases. To sum up, both strawberry seedling suppliers, planting and picking personnel, or fertilizer and pesticide suppliers, agricultural machinery and agricultural tools suppliers have strong bargaining power for strawberry growers.

\subsubsection{Resource suppliers in the marketing process}

Market sales are mainly divided into online and offline parts. Due to the short shelf life of strawberries, offline sales are mainly in the surrounding markets. In this process, strawberry middlemen become the main channel suppliers. When a large number of strawberries are produced, the demand saturation of the surrounding market is low. At this time, the channel suppliers will deliberately lower the price of strawberries and have strong bargaining power.

Online sales, mainly including packaging material suppliers, logistics providers, etc. At present, most strawberry packaging suppliers in Dandong area provide the same price, and there will be no increase in preferential sales due to large purchase, which undoubtedly increases the sales cost for strawberry growers. In addition, due to the short shelf life of strawberries, Shunfeng express and express delivery are often used to ensure the taste of the buyers. Therefore, the local logistics industry presents an oligarchy and has strong bargaining power.

\subsubsection{Threat capability of substitutes}

Although 99 strawberry in Dandong has a certain influence in the market, as a kind of fruit, there are many kinds of fruits to replace it. For example, the blueberries, apples and grapes planted in Dandong area have similar nutritional value with strawberries, and they are sold online and offline. Moreover, as the same variety of strawberry products, the strawberry produced in Jiangsu, Anhui, Yunnan and other places also occupies a certain position in the market. In addition, because strawberries are seasonal fruits and have a short listing cycle, in order to ensure the sales volume of strawberries and reduce losses, many businesses have made fresh strawberries into easily preserved frozen strawberries, canned strawberries and other derivatives to increase their added value. In a word, there are many related substitutes for strawberry in the market. Due to the strong threat of substitutes to Dandong strawberry, the overall strawberry sales market presents a buyer's market.

\subsubsection{Threat capability of potential entrants}

Tiktok Kwai has been gradually emerging in recent years. With the rapid development of many webcast platforms such as fast hand, jitter, and volcano videos, webcast has become a relatively widely used 99 strawberry sales channel. With WeChat becoming the platform for people to communicate, a large number of micro businesses are emerging in the circle of friends and official account. It is an inevitable choice to expand the sales market with the help of the network platform, but this way leads to the lower sales threshold of 99 strawberry. Some people use the strawberries from other regions to sell on the network platform, which affects the reputation and reputation of 99 strawberry in the market. This kind of potential entrant is also a threat to the sales market of 99 strawberry.

\subsubsection{Competitiveness of existing competitors in the industry}

At present, there are more than 100000 farmers engaged in strawberry planting, processing and sales in Dandong area. The annual output of strawberries reaches 420000 tons, and there are hundreds of online sales shops. Because it is located in rural areas, lack of innovative business philosophy, so everyone in the planting, packaging, sales and other aspects of a more serious homogenization phenomenon. In addition, the popularity of 99 strawberry is relatively high only in Northeast China. The strawberry produced in other areas of China also has a high recognition in the market, and the taste is quite similar to that of 99 strawberry. Therefore, for consumers, it is very likely to buy high-quality strawberries that are relatively close to their production areas. This is also a 
threat to the sales competition of 99 strawberry in the national market.

\section{COUNTERMEASURES TO ENHANCE THE COMPETITIVENESS OF 99 STRAWBERRY MARKET}

Through the analysis of "Porter's five forces" in Dandong 99 strawberry market competition, we found some problems in strawberry market. Therefore, we put forward the following suggestions and measures:

\subsection{Establish product brand strategy}

As the present strawberry market is full of good and bad people, there are many other varieties of strawberries full of the market under the banner of "99", so it is an inevitable trend to establish the brand strategy of "99" strawberry. First of all, we should make use of the variety advantages of 99 strawberry to strengthen the publicity of network media, so as to let more consumers know about its fruit shape, size, sweetness, taste and other advantages and quality level. In addition, consumers' recognition and loyalty to 99 strawberry will be increased, and the repurchase rate and competitiveness of consumers will be improved. The premise of consolidating the brand is to have high-quality products. Only by constantly improving the quality of strawberry and paying attention to the publicity of strawberry brand, can we form the competitive strategy of 99 strawberry's own brand. The formation of brand strategy is helpful for consumers to deepen their cognition of 99 strawberry and reduce the threat of "fake" products to a certain extent.

\subsection{Strengthen logistics infrastructure construction and improve distribution capacity}

The local government should strengthen the construction of logistics infrastructure, strengthen the construction of strawberry wholesale market and logistics center, and improve the circulation and distribution speed of strawberry ${ }^{[5]}$. Especially for strawberry, a kind of fruit with strong seasonality, short cycle, easy to rot and frostbite, we should build a separate distribution channel for rational distribution, so as to ensure that the "99" strawberry can be quickly and timely delivered to consumers and meet the demand of consumers for products. In addition, we should form a perfect distribution system, and provide fixed staff for centralized distribution of strawberry products packaged by farmers. In addition, we can carry out strategic cooperation with logistics parties in order to obtain lower distribution price, lengthen financial cycle and other financial conditions, as well as better services such as limited delivery, light handling when shipping.

\subsection{Optimize marketing channels and increase market share}

At present, the sales channels of 99 strawberry are mainly Taobao and wechat circle of friends. However, there are many Taobao merchants, a wide range of customers, and the source of customers is unstable. However, the scope of the circle of friends is limited, and the speed of developing new users is relatively slow, which limits the increase of strawberry market share to a certain extent. Therefore, strawberry growers can cooperate with Jingdong, pinduoduo and other sales platforms through multi platform drainage to attract more consumers and enhance their purchasing motivation. In addition, the development of high-quality live goods anchor, live in the sound, live broadcast tiktok, to attract more fans, and further expand the popularity of 99 strawberries nationwide.

\section{Conclusion}

99 strawberry is one of the main agricultural products planted in Dandong area. The value of its products has become the main source of local farmers' income, which has a certain role in promoting the local economic development. However, in the existing market, there are still many threats hindering the development of 99 strawberry. Therefore, with the help of Porter's five forces model, this paper analyzes the competitiveness of 99 strawberry in the market, finds out the existing competition problems, and puts forward the corresponding policy suggestions, so as to promote the long-term and stable development of the 99 strawberry market.

\section{REFERENCES}

1. He Meiying, Zhao Ping, Lin Yiying. Analysis on the market competitiveness of mango in China [J]. Acta AGRICULTURAE Sinica, 2020, 051 (003): p.722728.

2. Liang yong'an.analysis and Countermeasures of the industry competition structure of the third party cold chain logistics enterprises based on Porter's five forces model $[\mathrm{J}]$. Logistics engineering and management, 2020,42 (08): 87-89.

3. Zhang Jiaxin, Li Aihua. Research on the development of strawberry e-commerce in Dandong under the background of Internet $[\mathrm{J}]$. Liaoning Economic Journal, 2020, 000 (005): 52-53.

4. Lu Haining. Innovation path of marketing under the background of mobile Internet $[\mathrm{J}]$. China business theory, 2020 (17): 61-63.

5. Liu Huaihua. Research on the reconstruction and Countermeasures of agricultural enterprise competitiveness based on the Agricultural Internet of things [J]. Industry and Technology Forum, 2020,19 (14): 16-17. 